\title{
Experimental Investigation of the Effect of Sisal Fiber on the Partially Replaced Cement with Groundnut Shell Ash in Concrete
}

\author{
Sani J E*, Afolayan J O, Wilson U N, Eze OC, Nyeri J
}

Department of Civil Engineering, Nigerian Defence Academy, Kaduna, Nigeria.

* Corresponding Author: jesani@nda.edu.ng

\begin{abstract}
An investigation on the effect of sisal fiber on the partially replaced cement with Groundnut Shell Ash in Concrete was carried out. Sisal fiber of 3.5cm length which forms $1 \%$ of the mix by weight with groundnut shell ash as a partial replacement for cement was used in preparing the concrete specimen. Compressive strength test was carried out using $0 \%$, $5 \%, 10 \%, 15 \%, 20 \%, 25 \%$ and $30 \%$ of Groundnut shell ash as replacement of cement at different curing ages of 7, 14, 21 and 28 days. It was observed that at 7 and 14days of curing, it is needless introducing the GSA since the maximum compressive strength obtained were at $0 \%$ GSA. At 21 and 28days of curing, a considerable increase in compressive strength was observed for $5 \%$ and $10 \%$ of GSA. However, $5 \%$ of GSA can be regarded as the optimum content since it gives the maximum compressive strength value of $30.1 \mathrm{~N} / \mathrm{mm}^{2}$ at 28 days of curing. This is followed by $10 \%$ replacement of GSA yielding $28.10 \mathrm{~N} / \mathrm{mm}^{2}$ and then $0 \%$ GSA replacement yielding $25.01 \mathrm{~N} / \mathrm{mm}^{2}$.
\end{abstract}

Key words: Sisal fiber, Groundnut shell ash (GSA), Compressive strength, Curing ages, Concrete.

\section{Introduction}

The use of cement for construction in developing countries cannot be overemphasized. Also, the incessant increase in the price of Portland cement is attributable to possible overwhelming rate of demand in the construction industries. This has consequently compelled researchers to search for total or partial alternative building materials among several pozzolanic materials. Buari et al., (2013) describes groundnut shell ash (GSA) as a good pozzolanic material which reacts with calcium hydroxide forming calcium silicate hydrate. The specific gravity of the GSA was found to be less than that of the Ordinary Portland Cement (OPC) it replaced, this means that a considerable greater volume of cementitious materials will result from mass replacement of the OPC with the GSA. The investigation also showed that the compressive strength value of the GSA-OPC blended concrete at 10\% replacement level performed better and would be acceptable and considered as a good development for construction of masonry walls and mass foundations in low cost housing in Nigeria. Olutoge et al., (2013) investigated the Characteristics Strength and durability of GSA blended with cement concrete in Sulphate Environments. From the result of the tests and analysis carried out, it was deduced that the Groundnut Shell Ash blended with cement concrete has a proven resistance to magnesium sulphate, sodium sulphate and calcium sulphate media and would exhibit a better performance in soils containing these media $\left(\mathrm{MgSO}_{4}, \mathrm{Na}_{2} \mathrm{SO}_{4}, \mathrm{CaSO}_{4}\right.$.). It was also observed that there was a decrease in slump value with increase in GSA replacement which is reflective of the fact that GSA can reduce the consistency and ultimately, the workability of concrete. Alabadan et al., (2006) having used higher percentage of GSA reported that there is a decrease in the compressive strength of concrete produced as the percentages of GSA increases resulting in maximum strength of $16 \mathrm{~N} / \mathrm{mm} 2$ at 28 day of curing for $70 \% / 30 \%$ replacement. Likewise, Mujedu. and Adebara (2016) also carried out the experimental investigation using GSA as partial replacement in concrete varying the percentage from $0 \%$ to $75 \%$, at intervals of $15 \%$. The results presented showed that $15 \%$ GSA replacement produced concrete of $20.10 \mathrm{~N} / \mathrm{mm} 2$ compressive strength at 28 days of curing. Similarly, Ikumapayi (2018) worked on GSA as partial replacement of cement 
in concrete using lower percentage of replacement from $0 \%$ to $16 \%$. He reported that $4 \%$ replacement produced $16 \mathrm{~N} / \mathrm{mm}^{2}$ strength of concrete after 28days of curing.

It is important to mention that the limitations inherent in concrete as a building material for example, being poor or weak in tension, is also a reason for the litany of researches for how else it can be improved other the use of steel rods to reinforce it or complement its tensile strength. Many researches have been carried out in order to investigate the effect of addition of fibers on many strength properties of concrete such as tensile strength, compressive strength and flexural strength. Researches into the types of fibers to be used in concrete applications have been intensified since the 1950s alongside researches on the improvement of the composite materials technologies. Various types of fiber materials such as steel, carbon, glass, plastic, polypropylene, nylon, and cotton were tested. From the results of these researches, American Concrete Institute's (ACI) Committee 544 (2002) classified fiber reinforced concrete into four groups based on the fiber materials: steel fiber reinforced Concrete (SFRC), glass fiber reinforced concrete (GFRC), synthetic fiber reinforced concrete (SNFRC), and natural fiber reinforced concrete (NFRC). Synthetic fibers such as polyester, acrylic, polyethylene and polypropylene are further subdivided into micro- synthetic fibers (for diameter less than $0.30 \mathrm{~mm}$ ) and macrosynthetic fibers (for diameter greater than $0.30 \mathrm{~mm}$ ). Glass and natural fibers show vulnerability to temperature variation and environmental conditions, respectively, leaving steel and synthetic fibers as the most viable concrete reinforcement options. The focus of this experimental investigation is to establish the effect of sisal fibre on the properties of harden concrete partially replaced with groundnut shell ash. Having taking into consideration the experimental results of other researchers using GSA as partial replacement of cement in concrete without addition of Sisal fibre.

\section{Materials and methods}

\subsection{Materials used for the experiment}

The major materials used for this research work include the following fine aggregate, coarse aggregate, cement, sisal fiber, ground nut shell ash and clean water.

\subsubsection{Fine aggregate}

Fine aggregate sample was obtained from tipper garage at Sabon Yelwa Chikun LGA Kaduna, Kaduna State. It free from silt and debris that can inhibit the strength development of concrete. The coefficient of absorption of the fine aggregate used was $1 \%$ and the fineness value was 2.2 which indicate that it good for concrete since is not up to 3.2 value which is not suitable for concrete material. The maximum size of the fine aggregate is sizes less than $4.75 \mathrm{~mm}$.

\subsubsection{Coarse aggregate}

Crushed granite gravel having the minimum size of $7 \mathrm{~mm}$ and maximum size of $12 \mathrm{~mm}$ was chosen as the coarse aggregates, sample is obtained from tipper garage at Sabon Yelwa Chikun LGA Kaduna, Kaduna State.

\subsubsection{Cement}

Ordinary Portland cement of 53grade (ASTM C150 type I (2020)) with specific gravity of 3.25 was used for preparing the concrete mix. The cement used have the fineness of $3.65 \%$ which is below the value of $10 \%$ as specified by BS 4550: Part 3 (1978) which stated that percentage of cement sample retained on 45,90 band 300 micro meters sieve should not exceed $10 \%$. 


\subsubsection{Sisal fibre}

Sisal fiber sample was obtained from Tudun Wada market, Kaduna south LGA Kaduna, Kaduna State.

It was cut into $4 \mathrm{~cm}$ length. The sample of the sisal fibre used in this study is presented in Figure 1. The results of the research work carried out by Sani et al., (2017) on the properties of sisal fibre was adopted for this investigation as presented in Table 1.

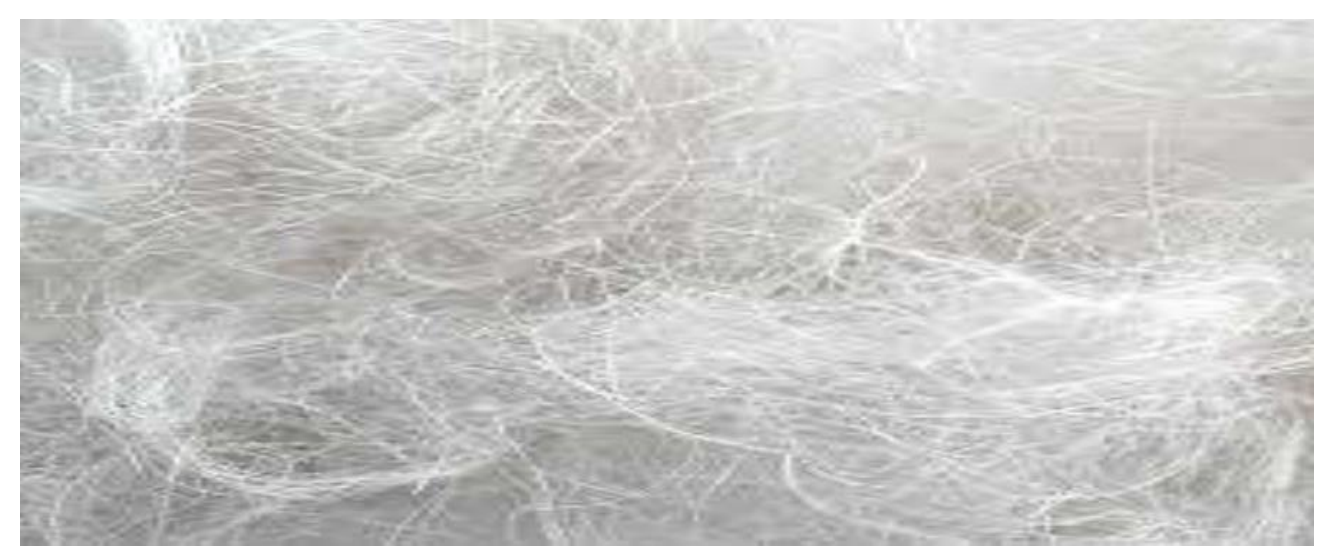

Fig. 1. Sample of Sisal fibre.

Table 1. Properties of the sisal fibre, (Sani et al., (2017))

\begin{tabular}{|c|c|}
\hline Property & Quantity \\
\hline \hline Natural humidity $\%$ & 14.48 \\
\hline Average diameter, $\mathrm{mm}$ & 0.13 \\
\hline Water absorption, $\%$ & 340 \\
\hline Specific gravity & 0.22 \\
\hline Tensile Strength of 1 strand $\mathrm{N} / \mathrm{mm}^{2}$ & 10.60 \\
\hline Tensile strength of 2 strands $/ \mathrm{mm}^{2}$ & 24.45 \\
\hline Tensile strength of 3 strands $\mathrm{N} / \mathrm{mm}^{2}$ & 30.60 \\
\hline Elongation at break, $\mathrm{mm}$ & 5.58 \\
\hline Colour & Shiny white \\
\hline
\end{tabular}

\subsubsection{Groundnut shell}

Groundnut shell sample is obtained from Television market Kaduna south LGA Kaduna, Kaduna State. The groundnut shell was sun dried and put in the open drum and burnt in ashes. This was grinded and sieved with $25 \mathrm{~mm}$ micro sieve. The sample of groundnut shell burnt to obtain the ash is shown in Figure 2 and the chemical composition of the groundnut shell ash (GSA) is as shown in Table 2 and it has the fineness of $7.8 \%$.

Table 2. Chemical Composition of Groundnut Shell Ash (GSA)

\begin{tabular}{|c|c|c|}
\hline Oxide & Percentage Composition & OPC (BS 12 Ranges) \\
\hline \hline $\mathrm{SiO}_{2}$ & 24.32 & $17-25$ \\
\hline $\mathrm{Al}_{2} \mathrm{O}_{3}$ & 5.31 & $3-8$ \\
\hline $\mathrm{Fe}_{2} \mathrm{O}_{3}$ & 1.01 & $0.5-6.0$ \\
\hline $\mathrm{CaO}$ & 8.93 & $60-67$ \\
\hline $\mathrm{MgO}$ & 5.34 & $0.1-4.0$ \\
\hline
\end{tabular}




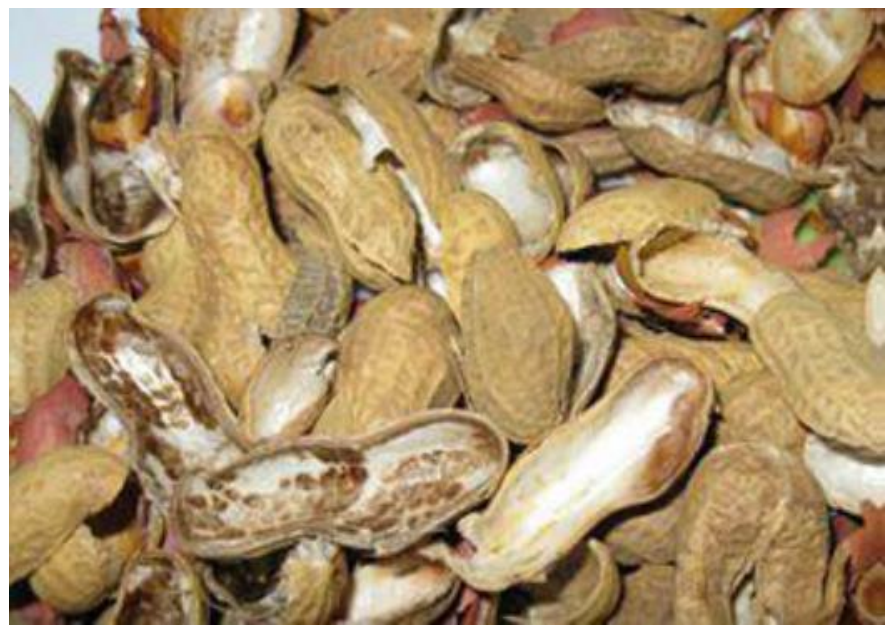

Fig. 2. Sample of Groundnut shell

\subsection{Methods}

The mix proportion of 1:2:3 was adopted using a mould size of $100 \times 100 \times 100 \mathrm{~mm}$. The mix proportion by mass constituted $3.63 \mathrm{~kg}$ of cement, $7.27 \mathrm{~kg}$ of fine aggregate (sand) and $11.76 \mathrm{~kg}$ of coarse aggregate with a water-cement ratio of 0.65 . Adequate mixing was done in order to produce a cement mortar of homogenous consistency as seen in Figure 3 . The concrete was first cast with $0 \%$ GSA, this is to serve as a control. Groundnut shell ash was then introduced as partial replacement of cement using 5\%,10\%,15\%,20\%,25\% and 30\% with sisal fiber of $3.5 \mathrm{~cm}$ length subsequently introduced of up to $1 \%$ of the concrete cube. A thin film petroleum jelly was used to the clean mould and also the contact surfaces of the bottom of the mould. After placing the concrete in the mould, the concrete was compacted using a rammer or tampering rod for 25 blows in 3 different layers. The cast cube in the mould was covered with an impervious sheet and allowed to set at room temperature for 24 hours. The concrete cube was removed from the mould, marked for identification and immersed in clean water for curing. The concrete cubes were tested at 7days, 14days, 21days and 28days of curing without fiber and $0 \%$ of GSA content to serve as control. Other concrete specimen were prepared containing $1 \%$ Sisal fiber as recommended by Sani et al., (2019) of average $3.5 \mathrm{~cm}$ length being added and the cement content being replaced partially with groundnut shell ash at 5\%,10\%,15\%,20\%,25\% and $30 \%$. The cubes were then tested at 7days, 14days, 21days and 28days of curing. A slump test was also carried out for all the varied proportions containing GSA replaced with cement.
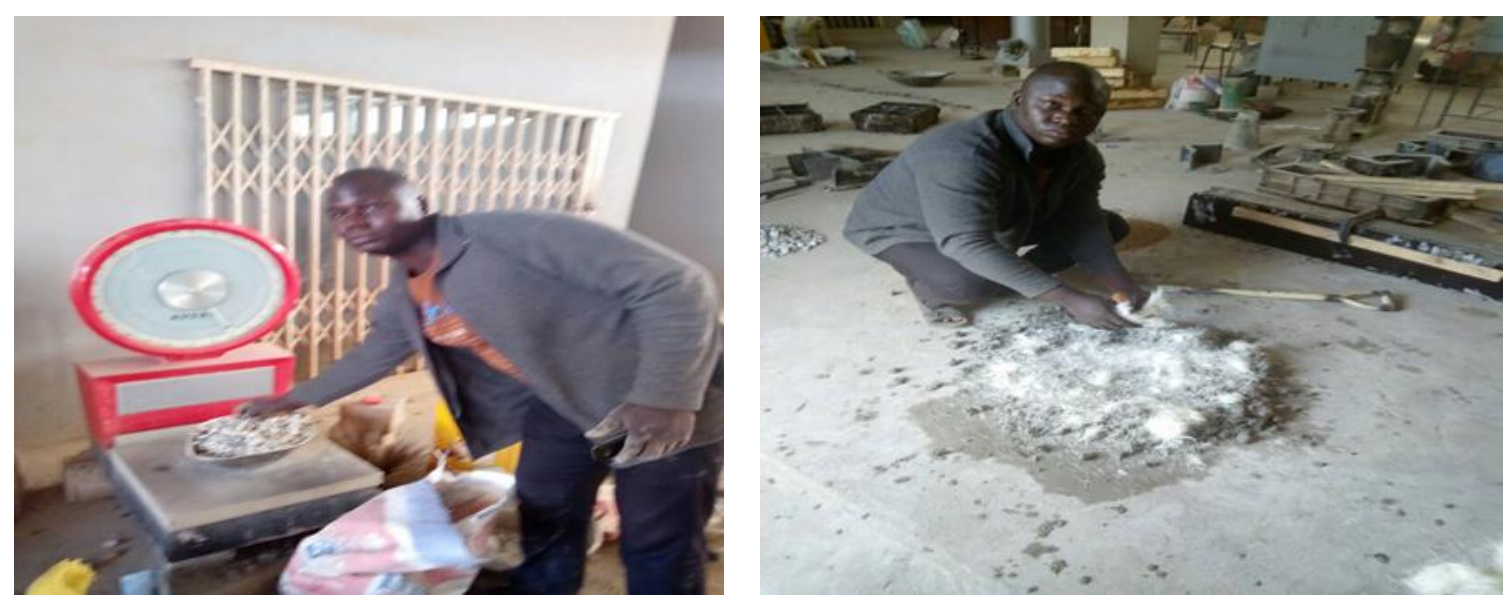

Fig. 3. Some procedures in the Experiment 


\subsubsection{Statistical analysis}

Statistical analysis was carried out on results obtained using analysis of variance (ANOVA) with the Microsoft Excel Analysis Tool Pak Software Package to determine the levels of significance of the effect of sisal fiber on partially replace Cement with groundnut shell ash in concrete.

\section{Results and discussion}

From the slump test carried out, the following results can be observed as seen in Figure 4. From the relationship between the percentage groundnut shell ash and the slump value, it can be deduced that the increase in the groundnut shell ash reduces the consistency and ultimately the workability of the concrete produced. This is traceable to the fact that increase in percentage addition of GSA requires higher water /cement ratio to produce a workable concrete without adding any water reducing agent.

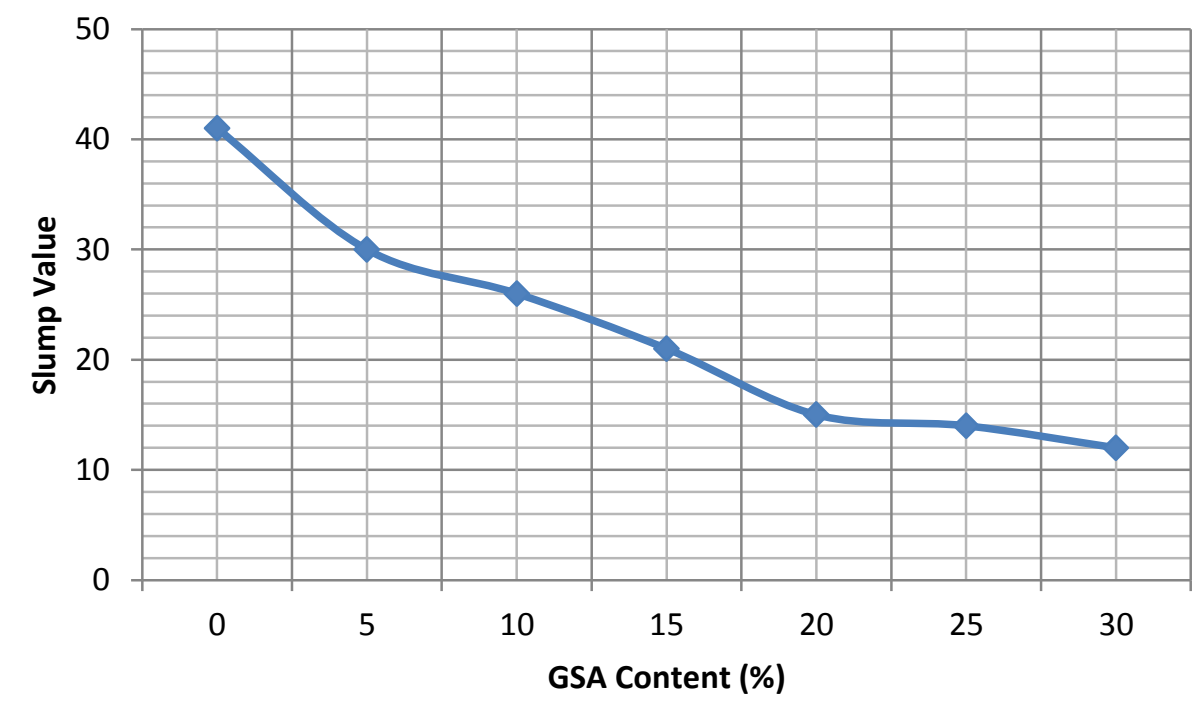

Fig. 4. Relationship between Slump value and the GSA percentages

It was observed that the inclusion of groundnut shell ash and sisal fiber in a concrete increased the compressive strength of concrete and the highest value of compressive strength was obtained at 5\% replacement of GSA in a sisal fiber-reinforced-concrete as seen in Figure 5. Significant increase in the compressive strength is recorded in 21 and 28 days of curing whose peaks are at $5 \%$ replacement in fiber reinforced concrete. This is different from other research findings whose assertion that $10 \%$ replacement level performs better and would be acceptable and considered as a good development for construction of masonry walls and mass foundations in low cost housing in Nigeria. The 5\% optimal replacement arrived at in this research is apparently owing to the sisal fibre introduced.

\section{Two-way analysis of variance (ANOVA)}

Two way analysis of variance tests was carried out to determine the level of significance of the effect of sisal fiber on partially replace Cement with groundnut shell ash in concrete and also the level of significance of the influence of curing age(days) on the compressive strength of the concrete. Table 3 shows the result of the two way analysis of variance. The two-way analysis of variance (ANOVA) for compressive strength of GSA replaced cement cured at different curing age (see Table 3) shows that the effect of GSA and curing period (days) on the compressive strength of concrete were statistically significant $\left(\mathrm{F}_{\mathrm{CAL}}=31.06699>\mathrm{F}_{\mathrm{CRIT}}=2.661305\right)$ for $\mathrm{GSA}$ 
replaced cement and $\left(\mathrm{F}_{\mathrm{CAL}}=129.459>\mathrm{FCRIT}=3.159908\right)$ for curing age (days). The effect of curing age (days) was more pronounced than that of GSA replace cement.

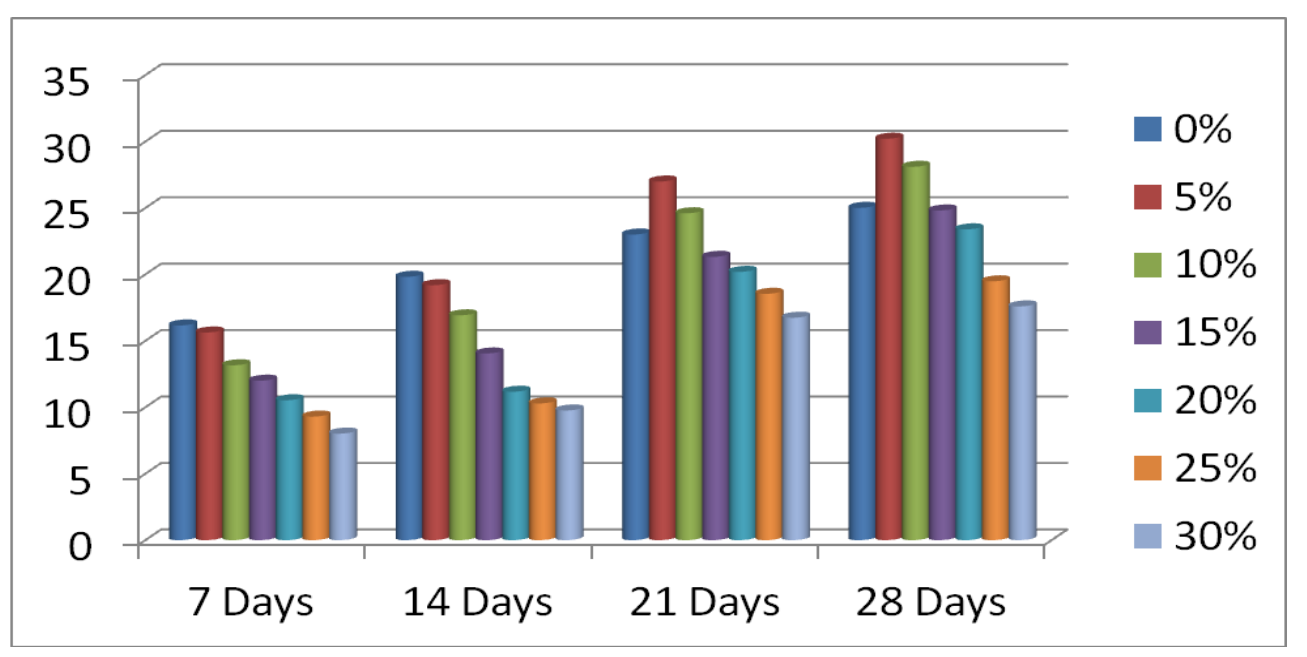

Fig. 5. Compressive Strength- Concrete Age Relation

Table 3. Two-way analysis of variance results for compressive strength of GSA replaced cement at different curing age (days).

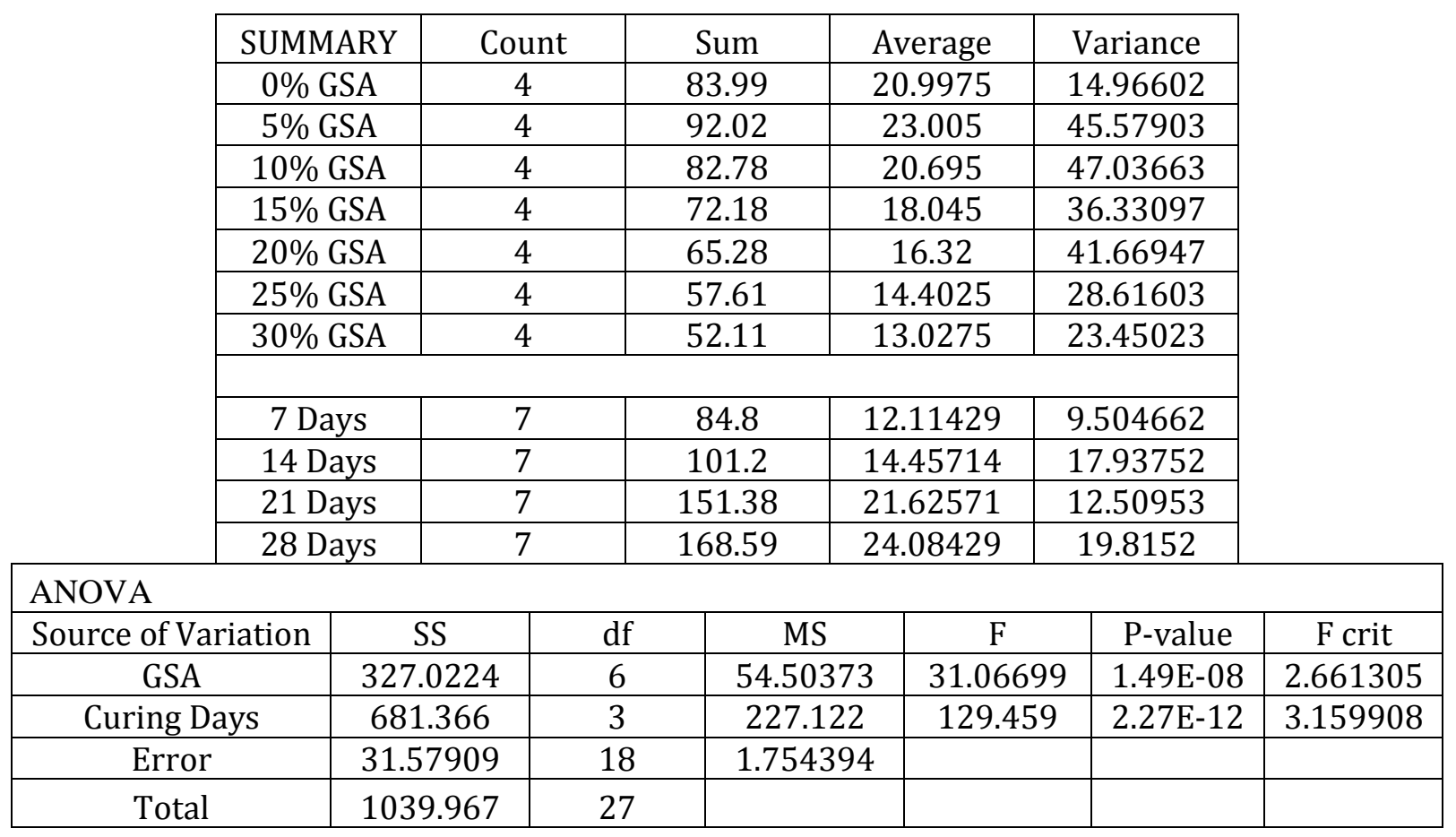

\section{Conclusion and Recommendation}

From the results of the study, it can be concluded that Groundnut Shell Ash used as partial replacement for cement with $1 \%$ of sisal fiber can significantly increase the compressive strength of a concrete. The compressive strength obtained between 5\%,10\% and $15 \%$ at 21 and 28 days of curing are satisfactory however, 5\% replacement of cement with GSA yields the highest compressive strength value and can hence be regarded as the optimal GSA content required for a sisal-reinforced-concrete. The strength at $10-15 \%$ groundnut shell ash replacement at 28 days of curing satisfies BS 4550 Part 3 section 3.4 requirements hence, the use of sisal fiber of up to $1 \%$ of the weight of concrete and $10 \%-15 \%$ of replaced cement with 
GSA at 28 days of curing provides compressive strength that is adequate and therefore can be recommended for mass concrete production.

\section{References}

ACI Committee 544 (2002). Design considerations for steel Fiber Reinforced Concrete, ACI 544.4R-88. American Concrete Institute, ACI Farmington Hills

Alabadan, B. A., Njoku, C. F., \& Yusuf, M. O. (2006). The potentials of groundnut shell ash as concrete admixture. Agricultural Engineering International: CIGR Journal. Manuscript BC 05 012, Vol. VIII.

ASTM C150: (2020). Standard Specification for Portland cement, American Society for Testing and Materials.

BS 4550 Part 3 (1978): Method of testing cement, British Standard Institution, Milton Keynes, London.

Buari, T. A., Ademola, S. A., \& Ayegbokiki, S. T. (2013). Characteristics Strength of groundnut shell ash (GSA) and Ordinary Portland cement (OPC) blended Concrete in Nigeria. IOSR Journal of Engineering (IOSRJEN), 3(7), 1-7.

Ikumapayi, C. M. (2018). Properties of groundnut shell (Arachis hypogaea) ash blended Portland cement. Journal of Applied Sciences and Environmental Management, 22(10), 1553-1556.

Mujedu, K. A., \& Adebara, S. A. (2016). The Use of Groundnut Shell Ash as a Partial Replacement for Cement in Concrete Production". International Journal of Sciences, Engineering and Environmental Technology (IJOSEET), 1(3), 32-39.

Olutoge, F. A., Buari, T. A., \& Adeleke, J. S. (2013). Characteristics strength and durability of groundnut shell ash (GSA) blended cement concrete in sulphate environment. International Journal of Scientific and Engineering, 4(7), 2122-2134.

Sani, J. E., Afolayan, J. O., Chukwujama, I. A., \& Yohanna, P. (2017). Effects of wood saw dust ash admixed with treated sisal fibre on the geotechnical properties of lateritic soil. Leonardo Electronic Journal of Practices and Technologies, (31), 59-76.

Sani, J. E., Hadiza, A. and Rintong, I. B. (2019). Effect of Inclusion of Randomly Oriented Jute Fibre Reinforcement on the Compressive Strength of Concrete. Nigerian Building and Road Research Institute International Conference Series. Theme: Construction Practices in Nigeria: Issues, Prospects \& Solutions 2 - 4 July, NAF Conference Centre, Kado, Abuja, Nigeria, Book of Abstracts, p. 37. 